\title{
TBDY-2018'deki Yerel Zemin Koşullarının Deprem Kesit Tesirlerine Etkisi
}

\section{Effect of Local Ground Conditions on Earthquake Section Effects in TBDY-2018}

\author{
Mehmet Hayrullah AKYILDIZ1*, Ali Emre ULU², Kübra ADAR ${ }^{3}$ \\ 1* Dicle Üniversitesi, İnşaat Mühendisliği Bölümü, Diyarbakır, Türkiye, hayrullah.akyildiz@ dicle.edu.tr ORCID ID: 0000-0001-7239-3518 \\ 2 Bitlis Eren Üniversitesi, İnşaat Mühendisliği Bölümü, 13000, Bitlis, Türkiye, aliemreulu @ gmail.com. tr ORCID ID:0000-0001-7499-3891 \\ ${ }^{3}$ Dicle Üniversitesi, İnşaat Mühendisliği Bölümü,Diyarbakır,Türkiye, kubra_adar05@hotmail.com.tr ORCID ID:0000-0001-6595-2879
}

\begin{tabular}{|c|c|}
\hline MAKALE BİLGİLERİ & ÖZ \\
\hline Makale Geçmişi: & \\
\hline $\begin{array}{l}\text { Geliş } 22 \text { Haziran } 2021 \\
\text { Revizyon } 24 \text { Eylül } 2021 \\
\text { Kabul } 27 \text { Eylül } 2021 \\
\text { Online } 28 \text { Eylül } 2021\end{array}$ & $\begin{array}{l}\text { Yerel zemin koşullarının, yapıların sismik davranışlarını etkilediği bilinen bir gerçektir. Son olarak } 2018 \\
\text { yılında güncellenmiş olan depreme dayanıklı yapı tasarım ilkeleri ile yerel zemin sınıfları da değişmiştir. } \\
\text { Bu değişimlerin basında, zeminin zayıf olduğu durumlara ve yüksek katlı yapılara özel yeni hesap } \\
\text { yaklaşımları getirmesidir. Dahası bu özel hesapları uzman kişilerce kontrolü zorunlu tutulmuştur. } \\
\text { Güncel deprem yönetmeliğinde yer alan yerel zemin koşulları dikkate alınarak örnek olarak seçilen }\end{array}$ \\
\hline $\begin{array}{l}\text { Anahtar Kelimeler: } \\
\text { Zemin kosulları, Zemin sinıfi, } \\
\text { Deprem, Kesit tesirleri, Deprem } \\
\text { yönetmeliği. }\end{array}$ & $\begin{array}{l}\text { betonarme bir yapıda yer alan bir düzlem çerçeve için deprem etkileri altında kesit tesirleri elde } \\
\text { edilmiştir. Bitlis iline ait herhangi bir coğrafi noktada, beş farklı yerel zemin sınfi için (ZA, ZB, ZC, ZD } \\
\text { ve ZE) öncellikle deprem parametrelerinin değişimi incelenmiştir. Her bir zemin sınıfı için kısa harita } \\
\text { spektral ivme katsayıları, en büyük yer ivmesi, en büyük yer hızı, spektral ivme katsayıları yatay ve } \\
\text { düşey elastik tasarım ivme spektrum köşe periyotları elde edilmiştir. Her bir yerel zemin sınıfı için elde } \\
\text { edilen değerler kullanılarak iki katlı bir betonarme yapı için hesaplamalar yapılarak deprem kesit tesirleri } \\
\text { hesaplanmıştır. Bu çalışma ile yeni yönetmelikteki zemin sınıflarının değişimi dikkate alınarak deprem } \\
\text { parametreleri ve kesit tesirleri üzerindeki etkileri hesaplanmıştır. }\end{array}$ \\
\hline
\end{tabular}

\begin{tabular}{|c|c|}
\hline ARTICLE INFO & ABSTRACT \\
\hline Article history: & \\
\hline $\begin{array}{l}\text { Received } 22 \text { June } 2021 \\
\text { Received in revised form } 24 \text { September } \\
2021 \\
\text { Accepted } 27 \text { September } 2021 \\
\text { Available online } 28 \text { September } 2021\end{array}$ & $\begin{array}{l}\text { It is a known fact that local ground conditions affect the seismic behavior of structures. Finally, with the } \\
\text { earthquake resistant building design principles updated in } 2018 \text {, local soil classes have also changed. At } \\
\text { the beginning of these changes is that it brings new calculation approaches specific to situations where } \\
\text { the ground is weak and high-rise buildings. Moreover, these special accounts are required to be } \\
\text { controlled by experts. Considering the local soil conditions in the current earthquake code, the section }\end{array}$ \\
\hline $\begin{array}{l}\text { Keywords: } \\
\text { Ground conditions, Soil class, } \\
\text { earthquake, Section effects, } \\
\text { Earthquake regulation }\end{array}$ & $\begin{array}{l}\text { effects under earthquake effects were obtained for a plane frame in a reinforced concrete structure } \\
\text { selected as an example. At any geographical point in the province of Bitlis, the variation of earthquake } \\
\text { parameters was examined for five different local soil classes (ZA, ZB, ZC, ZD and ZE). Short map } \\
\text { spectral acceleration coefficients, maximum ground acceleration, maximum ground velocity, spectral } \\
\text { acceleration coefficients, horizontal and vertical elastic design acceleration spectrum corner periods were } \\
\text { obtained for each soil class. Using the values obtained for each local soil class, calculations were made } \\
\text { for a two-storey reinforced concrete structure and the earthquake cross-section effects were calculated. } \\
\text { With this study, the effects on earthquake parameters and cross-section effects were calculated by taking } \\
\text { into account the change in soil classes in the new regulation. }\end{array}$ \\
\hline
\end{tabular}




\section{Giriş}

Ülkemiz, bulunduğu coğrafi konum sebebiyle etkin bir deprem bölgesi üzerinde yer almaktadır ve yıl içerisinde de farklı büyüklüklerde yüzlerce deprem meydana gelmektedir. Gerekli dayanım şartları sağlanmadığı takdirde bu depremler yapılara az, orta ya da büyük hasarlar verebilmektedir. Ülkemizin deprem bölgesi oluşu da üzerinde yapı düşünülen bütün nokta ve zeminlerin özelliklerini ve sınıflarını önemli kılmaktadır. Bu kapsamda hazırlanan deprem haritaları ve noktasal deprem spektrumları yapıların inşa edileceği zeminlerin ne tür özellikte ve yapıda olduğu hakkında bilgiler vermektedir.

Bu kapsamda, 2018 yılında Türkiye Bina Deprem Yönetmeliği (TBDY) yapıların daha güvenli ve dayanımlı olmalarını sağlamak açısından geliştirilerek güncellenmiştir. 2007'de yayımlanan Deprem Bölgelerinde Yapılacak Binalar Hakkında Yönetmelikte (DBYBHY) tabaka kalınlığı ve kayma dalga hızına göre dört adetle sınırlandırılan zemin sınıflandırılması, yeni yönetmelikte en iyi zeminden en kötü zemine göre sıralanarak altıya çıkarılmıştır (ZA, ZB, ZC, $Z D, Z E$ ve $Z F)$. Bu sinıflandırmada $Z A$ sinıfı en iyi zemini temsil etmektedir [1, 2]. ZF sınıfı zemin bu sıralamadaki en kötü zemin sınıfını ifade etmekle birlikte, bu zemin sınıfı için bir takım özel analizlerin yapılması ve yer hareket spektrumlarının kullanılması zorunluluğu getirilmiştir. Özel şartlara bağlı olan bu zemin sınıfına ait hesaplama ve değerlendirmeler bu çalışmada yer almamış diğer beş zemin türüne ait değerlendirmeler gerçekleştirilmiştir.

Yapılarda depremlere bağlı olarak oluşan farklı büyüklükteki hasarlar, yapıların deprem performanslarını incelemeyi ve değerlendirmeyi gerekli kılmıştır. Yapılarda depremlerden sonra meydana gelen bu hasarlar, sadece yapının değil zeminin de hasarlarda etkin bir rol oynadığı literatürdeki çalışmalardan anlaşılmaktadır [3, 4]. Ayrıca, zeminlerin bulunduğu konum, bulunduğu konumdaki yerel zemin sınıfları, tabii zemin eğimi gibi karakteristik özellikler de yapılarda meydana gelebilecek hasarları artırabilmektedir [5-7]. Deprem yükleri incelendiğinde yapılara hasar ve olumsuz etkiler verebilecek birçok değişken bulunmaktadır. $\mathrm{Bu}$ değişkenlerden en önemlilerinden birisi yapının üzerinde bulunduğu yerel zemin koşullarıdır [8-10]. Buna ek olarak, yapının bulunduğu bölgenin depremselliği, düzensizlik, yapıların bitişik veya ayrık nizamda oluşu, ağır çıkmalar ve yapısal özellikler deprem yüklerinin yapıya olan etkisini artıran parametrelerdir. Bu değişkenler yapının dayanımını düşürerek deprem sonrası meydana gelebilecek hasarları da artıracaktır [11-15].

Yeni yönetmelikle birlikte daha detaylı incelemeye tabi tutulan yerel zemin şartları ve deprem yer hareketi düzeyleri farklı yapılar üzerinde deprem yükleri, taban kesme kuvveti, eğilme momentleri, göreli kat ötelemeleri gibi parametreleri de etkilemektedir. Özellikle eşdeğer deprem yükleri ele alındığında DBYBHY2007' e göre azalma görülmektedir [16,17].

Bu çalışmada, her bir zemin sınıfı için ayrı ayrı olmak üzere, kısa harita spektral ivme katsayıları, en büyük yer ivmesi, en büyük yer hızı, spektral ivme katsayıları, yatay ve düşey elastik tasarım ivme spektrum köşe periyotları elde edilmiştir. Bunlara ek olarak, her bir yerel zemin sınıfı için elde edilen değerler kullanılarak beş katlı bir betonarme yap1 için hesaplamalar yapılarak deprem kesit tesirleri hesaplanmıştır. $\mathrm{Bu}$ çalışma ile zemin sınıflarının hem deprem yönetmeliklerindeki değişimi hem de güncel yönetmelik dikkate alınarak deprem parametreleri ve kesit tesirleri üzerindeki etkileri ayrı ayrı hesaplanmıştır.

\section{Materyal ve Metod}

Ülkemizde son çıkan yapı deprem yönetmeliği ile özel tasarım spektrumları geometrik konumlara bağlı olarak değişkenlik göstermeye başlamıştır. Yapılara etki eden deprem yükleri hesaplamalarında bazı parametreler gerekmektedir. $\mathrm{Bu}$ parametreler Türkiye Deprem Tehlike Haritaları İnteraktif Web Uygulaması kullanılarak elde edilmektedir. Bu uygulama, 2019 y1lında yürürlüğe giren TBDY ile birlikte kullanılmaktadır [18].

Çalışmada her bir zemin sınıfı için (ZA, ZB, ZC, ZD ve ZE) hesaplamalar yapılmıştır. $\mathrm{Bu}$ beş farklı zemin sınıfı dört farklı deprem yer hareket düzeyi (DD-1, DD-2, DD-3 ve DD-4) dikkate alınarak değerlendirmeler yapılmıştır. $\mathrm{Bu}$ sayede olası bir deprem durumunda yapının göstereceği eğilimler ve taşıyıcı sistemde meydana gelebilecek hasarlar belirlenmiş ve yapılarda zemin sınıflarından dolayı meydana gelen farklı kesit tesirleri belirlenerek değerlendirmeler yapılmıştır. Yapılan bu değerlendirme ile yapının ilk durum ve konumundan, kararsız duruma geçene kadarki sürede yapıdaki taban kesme kuvvetleri sonucu doğan deplasman değerleri elde edilir [19- 21]. Çalışma kapsamında rasgele olarak, Bitlis Merkezli 38,328162; 42,130669 konum noktası seçilerek, Şekil 1'de gösterilen İnteraktif Web Uygulamasından alınan; kısa periyot harita spektral ivme katsayısı, en büyük yer ivmesi, en büyük yer hızı, yerel zemin etki katsayıları, tasarım spektral ivme katsayıları ile yatay ve düşey elastik spektrum eğrisi değerleri okunarak hesaplamalar yapılmıştır. 


\section{TÜRKIYE DEPREM TEHLIKE HARITASI}

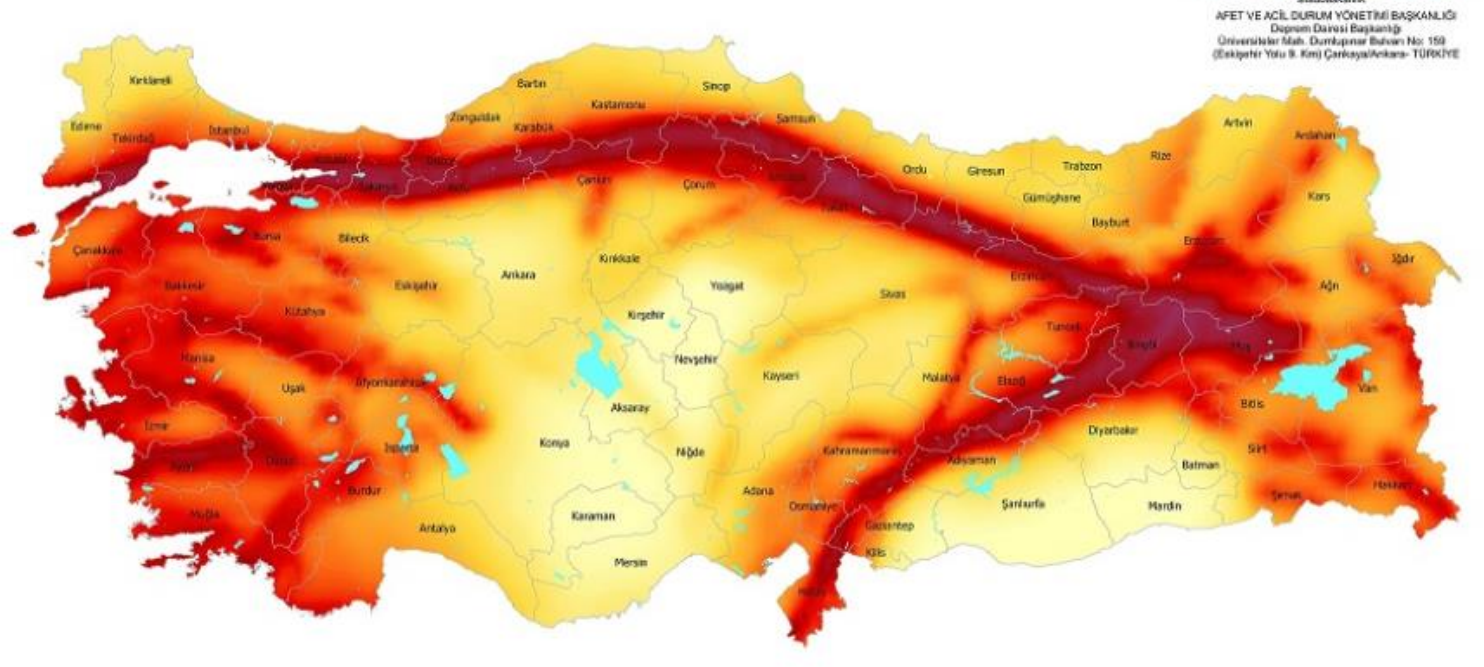

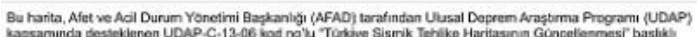

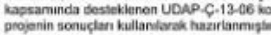

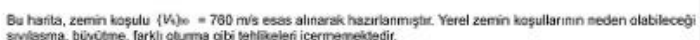

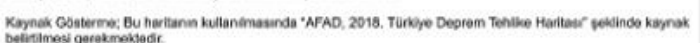

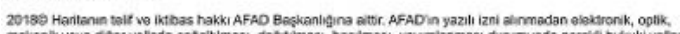

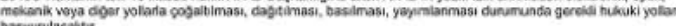

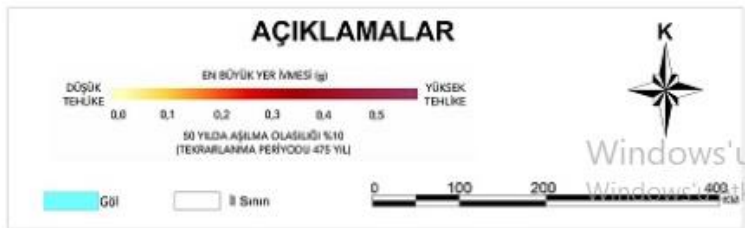

Şekil 1. Türkiye sismik tehlike haritası [18]

Türkiye Bina Deprem Yönetmeliği'nde (TBDY-2018), deprem yer hareket düzeyi önceki yönetmeliklerden farklı olarak dört farklı şekilde ifade edilmiştir. Çalışma kapsamında da kullanılan deprem yer hareket düzeyleri

\begin{tabular}{|c|c|c|c|}
\hline $\begin{array}{c}\text { Deprem } \\
\text { Düzeyi }\end{array}$ & $\begin{array}{c}\text { Tekrarlanma } \\
\text { Periyodu }\end{array}$ & $\begin{array}{c}\text { Aşılma } \\
\text { Olasllı̆̆ }(50 \\
\text { yılda) }\end{array}$ & Tanımı \\
\hline DD-1 & 2475 & 0.02 & $\begin{array}{c}\text { En büyük deprem yer } \\
\text { hareketi }\end{array}$ \\
\hline DD-2 & 475 & 0.1 & $\begin{array}{c}\text { Standart tas anm deprem } \\
\text { yer hareketi }\end{array}$ \\
\hline DD-3 & 72 & 0.5 & S1k deprem yer hareketi \\
\hline DD-4 & 43 & 0.68 & Servis deprem hareketi \\
\hline
\end{tabular}

Çizelge 1. Deprem yer hareketi düzeyleri [2]

Yeni deprem yönetmeliği ile zemin sınıflarının gösterimi de değişmiştir. Son deprem yönetmeliğinde yer alan zemin sınıfları ve özellikleri Çizelge 2'de verilmiştir.
Çizelge 1'de verilmiştir. Dört farklı deprem yer hareket düzeyi için deprem parametre değerleri ayrı ayrı hesaplanmıştır. 


\begin{tabular}{|c|c|c|c|c|}
\hline \multirow{2}{*}{$\begin{array}{c}\text { Yerel } \\
\text { Zemin } \\
\text { Sinıfi }\end{array}$} & \multirow[b]{2}{*}{ Zemin Cinsi } & \multicolumn{3}{|c|}{ Ûst 30 metrede ortalama } \\
\hline & & $\begin{array}{c}\left(V_{\mathrm{s}}\right)_{30} \\
{[\mathrm{~m} / \mathrm{s}]}\end{array}$ & $\begin{array}{c}\left(N_{60}\right)_{30} \\
\text { [darbe } / 30 \mathrm{~cm}]\end{array}$ & $\begin{array}{l}\left(c_{\mathrm{u}}\right)_{30} \\
{[\mathrm{kPa}]}\end{array}$ \\
\hline $\mathrm{ZA}$ & Sağlam, sert kayalar & $>1500$ & - & - \\
\hline ZB & Az ayrışmış, orta sağlam kayalar & $760-1500$ & - & - \\
\hline $\mathrm{ZC}$ & $\begin{array}{l}\text { Çok sıkı kum, çakıl ve sert kil tabakaları veya } \\
\text { ayrışmış, çok çatlaklı zayıf kayalar }\end{array}$ & $360-760$ & $>50$ & $>250$ \\
\hline $\mathrm{ZD}$ & $\begin{array}{l}\text { Orta sıkı - sıkı kum, çakıl veya çok katı kil } \\
\text { tabakaları }\end{array}$ & $180-360$ & $15-50$ & $70-250$ \\
\hline ZE & $\begin{array}{l}\text { Gevşek kum, çakıl veya yumuşak - katı kil } \\
\text { tabakaları veya } \\
P I>20 \text { ve } w>\% 40 \text { koşullarını sağlayan } \\
\text { toplamda } 3 \text { metreden daha kalın yumuşak kil } \\
\text { tabakası }\left(c_{\mathrm{u}}<25 \mathrm{kPa}\right) \text { içeren profiller }\end{array}$ & $<180$ & $<15$ & $<70$ \\
\hline $\mathrm{ZF}$ & \multicolumn{4}{|c|}{$\begin{array}{l}\text { Sahaya özel araștırma ve değerlendirme gerektiren zeminler: } \\
\text { 1) Deprem etkisi altında çökme ve potansiyel göçme riskine sahip zeminler (sıvılaşabilir zeminler, } \\
\text { yüksek derecede hassas killer, göçebilir zayıf çimentolu zeminler vb.), } \\
\text { 2) Toplam kalınlığı } 3 \text { metreden fazla turba ve/veya organik içeriği yüksek killer, } \\
\text { 3) Toplam kalınlığı } 8 \text { metreden fazla olan yüksek plastisiteli }(P I>50) \text { killer, } \\
\text { 4) Cok kalın }(>35 \text { m) yumușak veya orta katı killer. }\end{array}$} \\
\hline
\end{tabular}

Çizelge 2. Yerel zemin sinıfları [2]

Türkiye Deprem Tehlike Haritaları İnteraktif Web Uygulaması kullanılarak seçilen geometrik konum için farklı deprem yer hareket düzeyleri için en büyük yer ivmesi (PGA), en büyük yer hızı (PGV) değerlerinin karşılaştırılması Çizelge 3'te gösterilmiştir.

\begin{tabular}{|c|c|c|c|c|c|c|c|}
\hline \multicolumn{3}{|c|}{ En büyük yer ivmesi (g) } & \multicolumn{5}{c|}{ En büyük yer hızı (cm/s)-PGV } \\
\hline \multicolumn{3}{|c|}{50 yılda aşılma olasılığı } & \multicolumn{5}{c|}{50 yılda aşılma olasılığı } \\
\hline $2 \%$ & $10 \%$ & $50 \%$ & $68 \%$ & $2 \%$ & $10 \%$ & $50 \%$ & $68 \%$ \\
\hline 0.489 & 0.259 & 0.105 & 0.075 & 27.742 & 14.714 & 6.308 & 4.685 \\
\hline
\end{tabular}

Çizelge 3. Farklı aşılma olasılıkları için elde edilen PGA ve PGV değerleri

Türkiye Deprem Tehlike Haritaları İnteraktif Web Uygulaması kullanılarak farklı deprem yer hareket düzeyleri için kısa periyot harita spektral ivme katsayısı (SS), 1.0 saniye periyot için harita spektral ivme katsayısı (S1), değerlerinin karşılaş̧tırılması Çizelge 4'te gösterilmiştir.

\begin{tabular}{|c|c|c|c|c|c|c|c|}
\hline \multicolumn{3}{|c|}{ Kısa periyot ivme katsayısı } & \multicolumn{4}{|c|}{$\begin{array}{c}1.0 \text { saniye periyot için harita } \\
\text { spektral ivme katsayısı }\end{array}$} \\
\hline \multicolumn{3}{|c|}{50 yılda aşılma olasılı̆ı } & \multicolumn{5}{|c|}{50 yılda aşılma olasılı̆ı } \\
\hline $2 \%$ & $10 \%$ & $50 \%$ & $68 \%$ & $2 \%$ & $10 \%$ & $50 \%$ & $68 \%$ \\
\hline 1.190 & 0.610 & 0.239 & 0.172 & 0.305 & 0.168 & 0.074 & 0.054 \\
\hline
\end{tabular}

Çizelge 4. Farklı aşılma olasılıkları için elde edilen SS veS1 değerleri

Yerel zemin etki katsayıları (FS ve F1), tasarım spektral ivme katsayıları (Kısa periyot tasarım spektral ivme katsayısı (SDS) ile 1.0 saniye periyot için tasarım spektral ivme katsayısı (SD1)) ve yatay ile düssey elastik spektrum değerleri ayrı ayrı hesaplanmıştır. Farklı yer hareket düzeyleri ve zemin sınıfları için elde edilen değerlerin karşılaştırılması Çizelge 5'te verilmiştir.

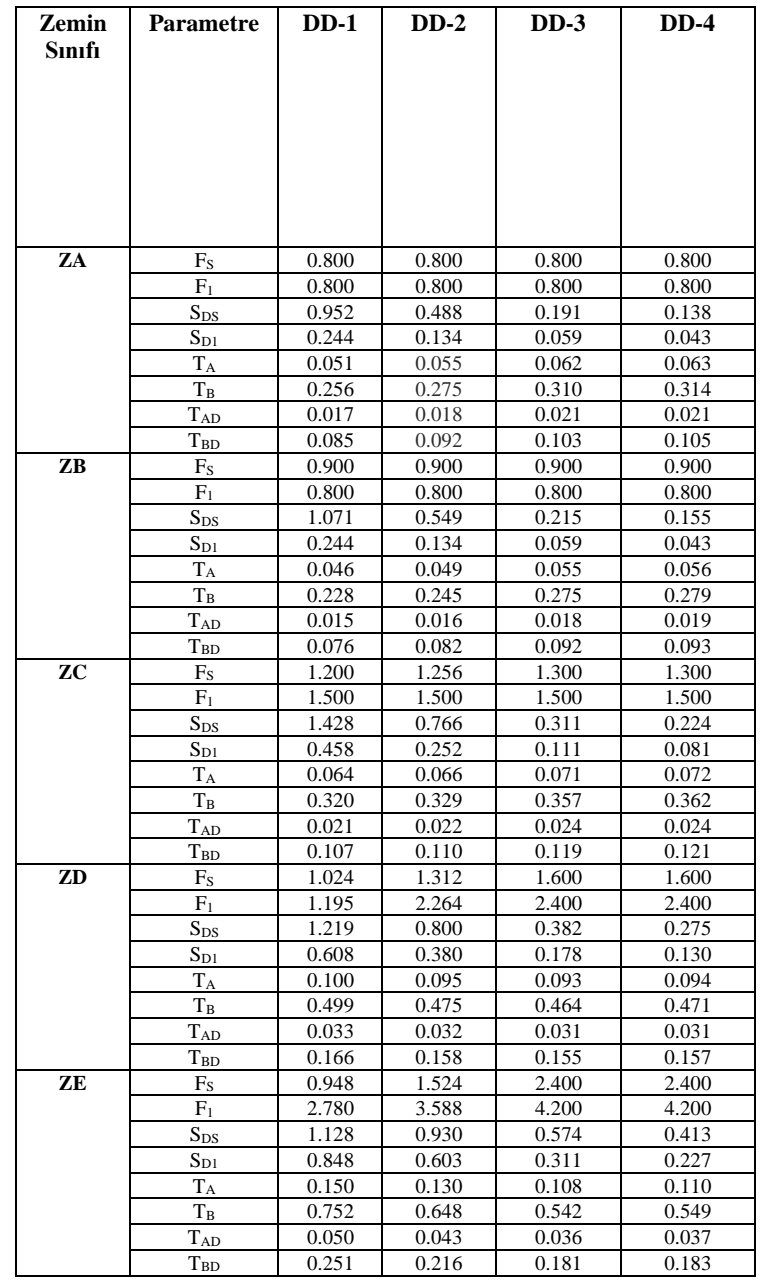

Çizelge 5. Deprem parametre değerlerinin farklı yer hareketleri ve zemin sınıfları için karşılaştırılması

Çalışmada dikkate alınan coğrafik konum için uygulama üzerinden elde edilen farklı aşılma olasılıkları için en büyük yer ivme haritaları Şekil 2'de gösterilmiştir. 


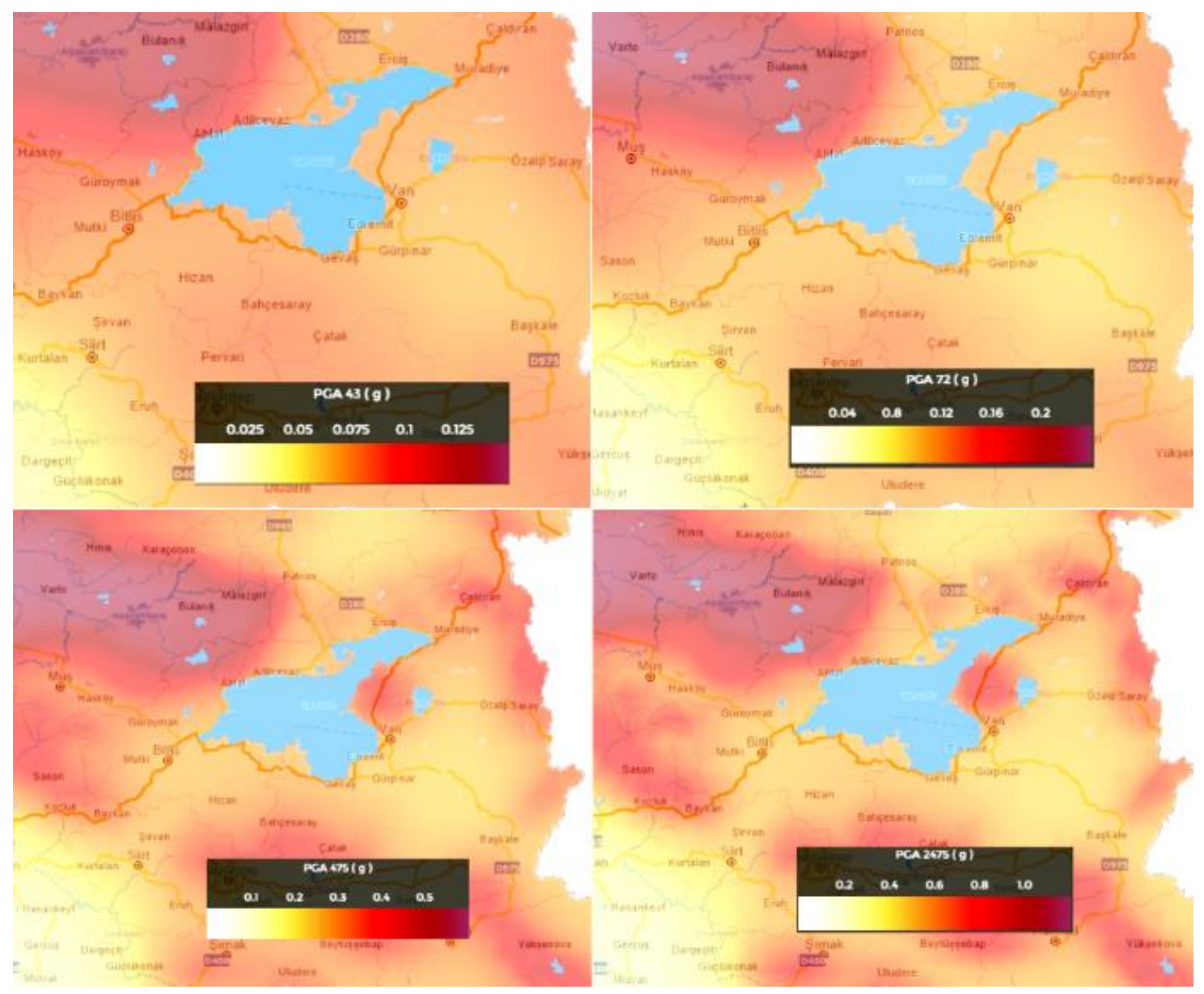

Şekil 2. Farklı yer aşılma olasılıkları için en büyük ivme değerlerini gösteren haritalar

Yapılan çalışmada, seçilen noktaya ait zemin sınıflarında kullanılacak olan spektrum değerleri Türkiye Deprem Haritaları internet ara yüzü kullanılarak her bir deprem düzeyi için elde edilmiştir. Farklı zemin grupları için elde edilen yatay ve düşey tasarım spektrumlarının karşılaştırılması Şekil 3, 4, 5, ve 6'da gösterilmiştir. 

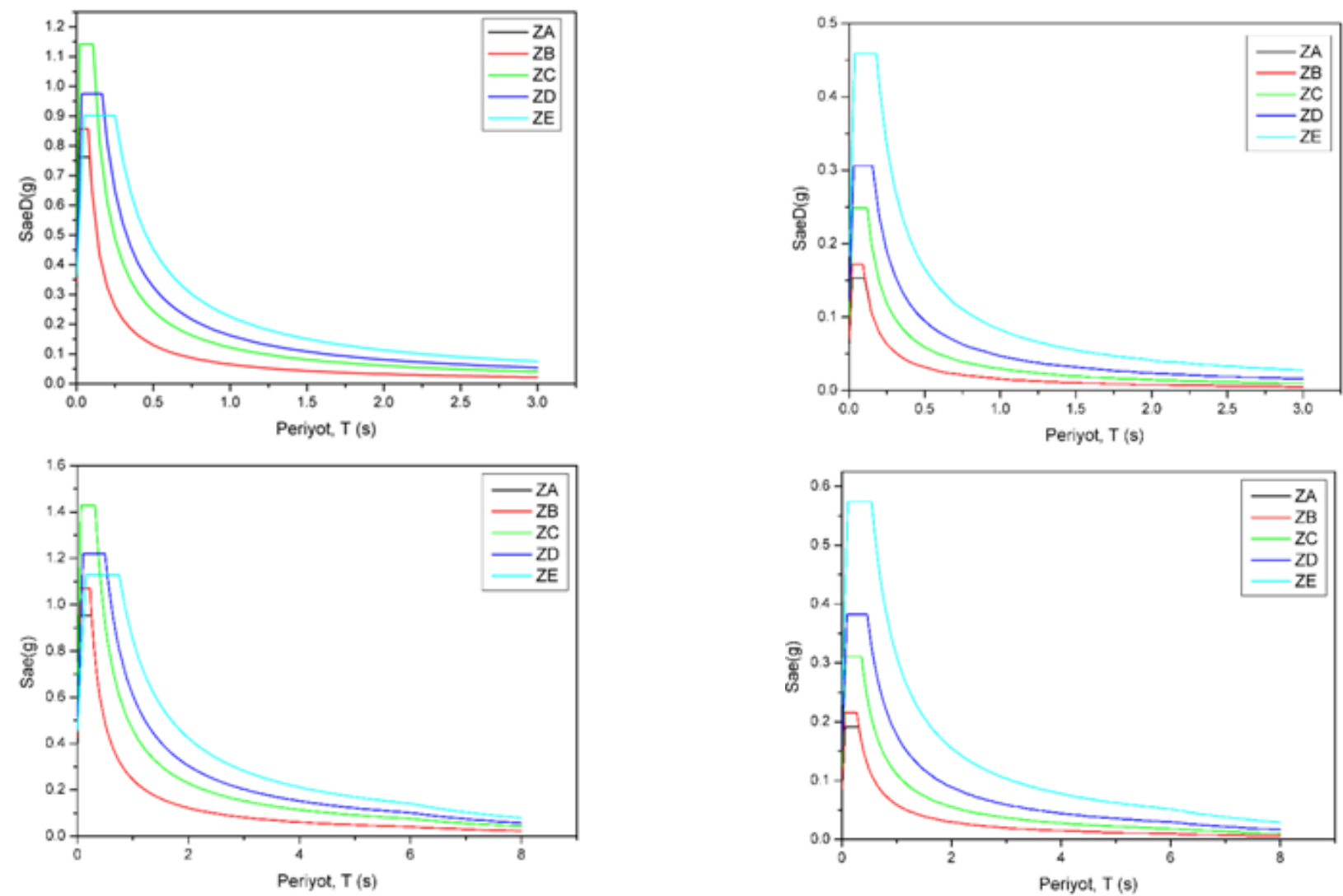

Şekil 3. DD-1 Tasarım Spektrum Eğrileri (a) Düşey, (b) Yatay

Şekil 5. DD-3 Tasarım Spektrum Eğrileri (a) Düşey, (b) Yatay
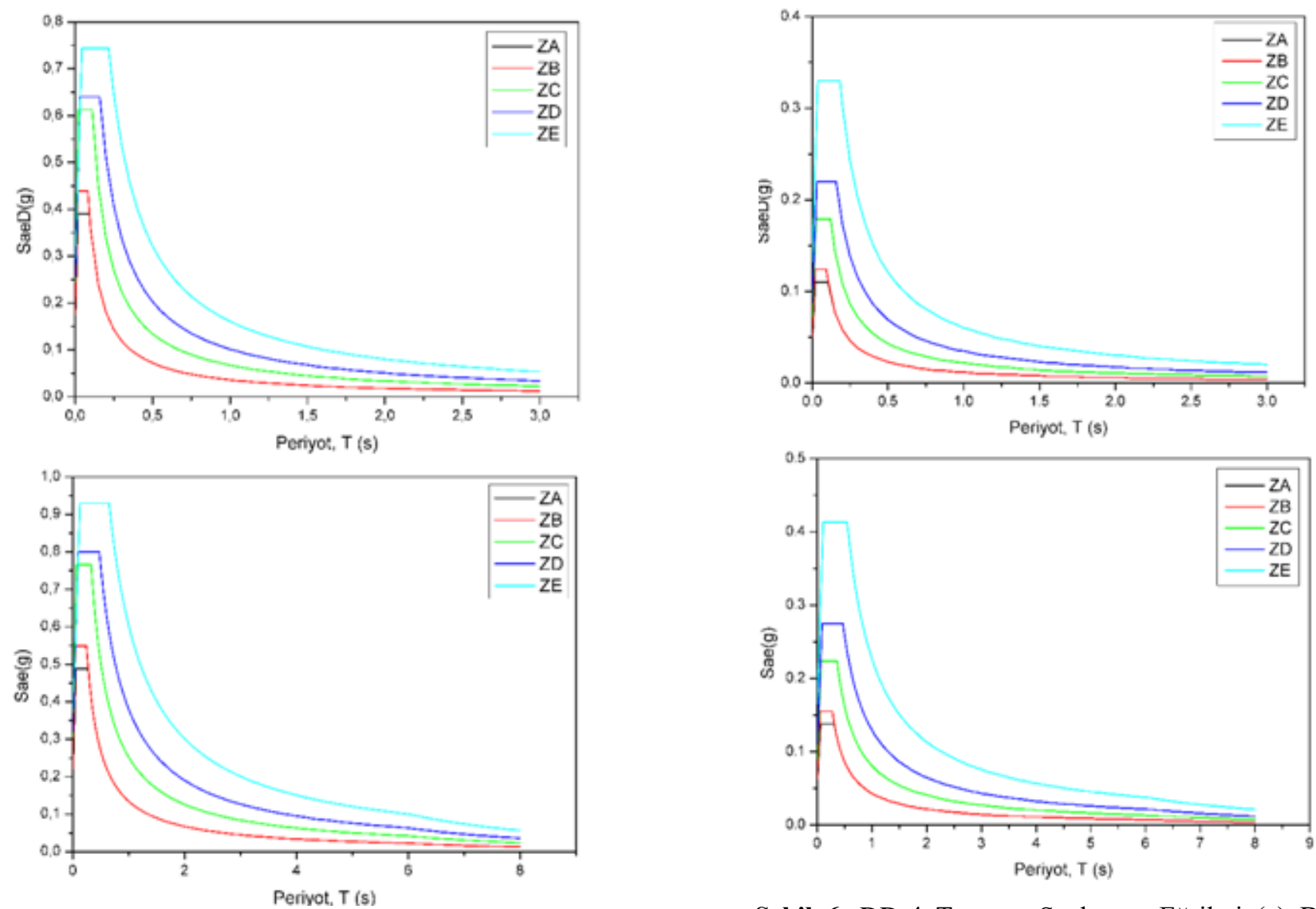

Şekil 4. DD-2 Tasarım Spektrum Eğrileri (a) Düşey, (b) Yatay

Şekil 6. DD-4 Tasarım Spektrum Eğrileri (a) Düşey, (b) Yatay 


\section{Araştırma Bulguları}

Çalışmada, 2 katlı 2 açıklıklı betonarme düzlem çerçeve modeli kullanılmıştır. Betonarme yapı TBDY-2018 şartlarına uygun olarak tasarlanmıştır. Beton sınıfı C30/37, çelik B420C, kat yükseklikleri tüm katlarda $3.00 \mathrm{~m}$ ve açıklık uzunlukları $4.00 \mathrm{~m}$ olarak seçilmiştir. Tüm katlarda kiriş boyutları $25 * 50 \mathrm{~cm}$, kolon boyutları ise $30 * 60 \mathrm{~cm}$ 'dir. Katlar rijit diyafram olarak tasarlanıp kiriş ve kolonlar için yönetmelikte belirtilen etkin rijitlik katsayıları tanımlanmıştır. Ölü yük değeri dış kirişlerde $8 \mathrm{kN} / \mathrm{m}$, iç kirişlerde $6 \mathrm{kN} / \mathrm{m}$ ve tüm kirişlere gelen hareketli yük 5 $\mathrm{kN} / \mathrm{m}$ olarak kabul edilmiştir. Hareketli yük katılım katsayısı ise bina olduğundan kaynaklı 0,3 alınmıştır. Çizelge 6'da ZA deprem sınıfına bağlı olarak diğer katsayıların değişim oranları gösterilmiştir.

\begin{tabular}{|c|c|c|c|c|c|}
\hline & ZA & ZB (\%) & ZC (\%) & ZD (\%) & ZE $(\%)$ \\
\hline$F_{\mathbf{S}}$ & 0 & 12.5 & 57.0 & 64.0 & 90.5 \\
\hline $\mathbf{F}_{\mathbf{1}}$ & 0 & 0 & 87.5 & 183.0 & 348.5 \\
\hline $\mathbf{S}_{\mathbf{D S}}$ & 0 & 12.5 & 57.0 & 64.0 & 90.6 \\
\hline $\mathbf{S}_{\mathbf{D} \mathbf{1}}$ & 0 & 0 & 88.1 & 183.6 & 350.0 \\
\hline
\end{tabular}

Çizelge 6. ZA sınıfına bağlı olarak ZB, ZC, ZD ve ZE sınıfı değer oranı

Değerler hesaplanırken TBDY-2018'de belirtilen tasarım ve doğrusal hesap yöntemleri kullanılalarak hesaplanmış ve yönetmelikteki şartların sağlanma kontrolü yapılmıştır. Katlara etkiyen eşdeğer deprem yükü yönetmelikte bulunan aşağıdaki formül ile hesaplanmıştır.

$$
V_{t E}^{(X)}=\Delta F_{N E}^{(X)}+\sum_{i=1}^{N} F_{i E}^{(X)}
$$

Burada:

$\Delta F_{N E}^{(X)}=N^{\prime}$ inci kata etkiyen ek eşdeğer deprem yüküdür ve bu değer yine yönetmelikte verilen:

$$
\Delta F_{N E}^{(X)}=0.0075 N V_{t E}^{(X)}
$$

formülü ile belirlenmiştir. Toplam eşdeğer yükün dışında kalan kısım ise bina katlarına aşağıdaki formül kullanılarak dağıtılmıştır.

$$
F_{i E}^{(X)}=\left(V_{t E}^{(X)}-\Delta F_{N E}^{(X)}\right)+\frac{m_{i} H_{i}}{\sum_{j=1}^{N} m_{j} H_{j}}
$$

Kolon ve kirişlere etkiyen kuvvetler MUTO yöntemiyle hesaplanarak çizelgeler oluşturulmuştur. Çizelge 7, 8, 9, 10

\begin{tabular}{|c|c|c|c|c|c|c|c|c|c|}
\hline Kat No & $\begin{array}{c}\text { Kolo } \\
\text { n } \\
\text { Adı }\end{array}$ & $\begin{array}{c}\mathbf{k}_{\mathbf{c}} \\
\left(\mathbf{x} 10^{4}\right)\end{array}$ & $\begin{array}{l}\mathbf{k}^{\prime} \\
\end{array}$ & a & $\begin{array}{c}\mathbf{D}_{4}^{\left(\mathbf{x} 10^{-}\right.} \\
.\end{array}$ & $\mathbf{v}$ & $\mathbf{Y}_{\mathbf{x}}$ & $\begin{array}{c}\mathbf{M} \text { (üs } \\
\text { t) }\end{array}$ & $\begin{array}{c}\mathrm{M}(\mathbf{a l} \\
\mathbf{t})\end{array}$ \\
\hline \multirow[t]{3}{*}{2} & S204 & 2,63 & $\begin{array}{c}2,9 \\
2 \\
2\end{array}$ & $\begin{array}{c}0,5 \\
9 \\
9\end{array}$ & 1,56 & $\overline{3,92}$ & $\begin{array}{c}0,4 \\
5\end{array}$ & 6,47 & 5,30 \\
\hline & S205 & 4,98 & $\begin{array}{c}3,1 \\
1\end{array}$ & $\begin{array}{c}0,6 \\
1\end{array}$ & 3,03 & 7,64 & $\begin{array}{c}0,4 \\
5\end{array}$ & 12,60 & 10,31 \\
\hline & S206 & 2,63 & $\begin{array}{c}2,9 \\
9\end{array}$ & $\begin{array}{c}0,6 \\
0\end{array}$ & 1,57 & 3,96 & $\begin{array}{c}0,4 \\
5\end{array}$ & 6,54 & 5,35 \\
\hline Toplam & & & & & 6,16 & $\begin{array}{c}15,5 \\
2\end{array}$ & & 25,61 & 20,96 \\
\hline
\end{tabular}
ve 11 zemin sınıflarına göre hesaplanarak elde edilen çubuk uç kuvvetlerini göstermektedir.

\begin{tabular}{|c|c|c|c|c|c|c|c|c|c|}
\hline $\begin{array}{l}\text { Kat } \\
\text { No }\end{array}$ & $\begin{array}{l}\text { Kolo } \\
\text { n Adı }\end{array}$ & $\begin{array}{c}\mathbf{k}_{\mathrm{c}} \\
\left(\mathbf{x 1 0 ^ { 4 }}\right)\end{array}$ & $\mathbf{k}^{\prime}$ & a & $\begin{array}{c}\text { D (x10 } \\
4)\end{array}$ & $\mathbf{V}$ & $\mathbf{Y}_{\mathbf{X}}$ & $\begin{array}{c}\text { M(üst } \\
\text { ) }\end{array}$ & $\begin{array}{c}\text { M(alt } \\
\text { ) }\end{array}$ \\
\hline \multirow[t]{3}{*}{2} & S204 & 2,63 & $\begin{array}{c}2,9 \\
2\end{array}$ & $\begin{array}{c}0,5 \\
9\end{array}$ & 1,56 & 4,14 & $\begin{array}{c}0,4 \\
5\end{array}$ & 6,83 & 5,59 \\
\hline & S205 & 4,98 & $\begin{array}{c}3,1 \\
1\end{array}$ & $\begin{array}{c}0,6 \\
1\end{array}$ & 3,03 & 8,05 & $\begin{array}{c}0,4 \\
5\end{array}$ & 13,29 & 10,87 \\
\hline & S206 & 2,63 & $\begin{array}{c}2,9 \\
9\end{array}$ & $\begin{array}{c}0,6 \\
0\end{array}$ & 1,57 & 4,18 & $\begin{array}{c}0,4 \\
5\end{array}$ & 6,90 & 5,64 \\
\hline $\begin{array}{c}\text { Topla } \\
\text { m }\end{array}$ & & & & & 6,16 & $\begin{array}{c}16,3 \\
7\end{array}$ & & 27,01 & 22,10 \\
\hline \multirow[t]{3}{*}{1} & S104 & 2,63 & $\begin{array}{c}2,9 \\
2\end{array}$ & $\begin{array}{c}0,6 \\
9\end{array}$ & 1,82 & 6,81 & $\begin{array}{c}0,5 \\
8\end{array}$ & 8,69 & 11,75 \\
\hline & S105 & 4,98 & $\begin{array}{c}3,1 \\
1\end{array}$ & $\begin{array}{c}0,7 \\
1\end{array}$ & 3,52 & $\begin{array}{c}13,1 \\
4\end{array}$ & $\begin{array}{c}0,5 \\
8\end{array}$ & 16,75 & 22,67 \\
\hline & S106 & 2,63 & $\begin{array}{c}2,9 \\
9\end{array}$ & $\begin{array}{c}0,7 \\
0\end{array}$ & 1,84 & 6,86 & $\begin{array}{c}0,5 \\
8\end{array}$ & 8,74 & 11,83 \\
\hline $\begin{array}{c}\text { Topla } \\
\text { m }\end{array}$ & & & & & 7,18 & $\begin{array}{c}26,8 \\
1\end{array}$ & & 34,18 & 46,25 \\
\hline
\end{tabular}

\begin{tabular}{|l|c|c|c|c|c|c|c|c|c|}
\hline $\mathbf{1}$ & S104 & 2,63 & $\begin{array}{c}2,9 \\
2\end{array}$ & $\begin{array}{c}0,7 \\
0\end{array}$ & 1,82 & $\begin{array}{c}6,46 \\
0,5\end{array}$ & $\begin{array}{c}8,24 \\
8\end{array}$ & 11,15 \\
\cline { 2 - 10 } & S105 & 4,98 & $\begin{array}{c}3,1 \\
2\end{array}$ & $\begin{array}{c}0,7 \\
1\end{array}$ & 3,52 & $\begin{array}{c}12,4 \\
6\end{array}$ & $\begin{array}{c}0,5 \\
8\end{array}$ & 15,89 & 21,49 \\
& & & & & & & \\
\cline { 2 - 10 } & S106 & 2,63 & $\begin{array}{c}2,9 \\
9\end{array}$ & $\begin{array}{c}0,7 \\
0\end{array}$ & 1,84 & 6,50 & $\begin{array}{c}0,5 \\
8\end{array}$ & 8,29 & 11,22 \\
\hline \multirow{2}{*}{ Toplam } & & & & & $\mathbf{7 , 1 7}$ & $\begin{array}{c}\mathbf{2 5 , 4} \\
\mathbf{2}\end{array}$ & & $\mathbf{3 2 , 4 1}$ & $\mathbf{4 3 , 8 5}$ \\
\hline
\end{tabular}

Çizelge 7. Muto Metoduyla Çubuk ZA Uç Kuvvetleri

\begin{tabular}{|c|c|c|c|c|c|c|c|c|c|}
\hline $\begin{array}{c}\text { Kat } \\
\text { No } \\
\end{array}$ & $\begin{array}{c}\text { Kolon } \\
\text { Adı }\end{array}$ & $\begin{array}{c}\mathbf{k}_{\mathrm{c}} \\
\left(\mathbf{x 1 0}^{4}\right)\end{array}$ & $\mathbf{k}^{\prime}$ & $\mathbf{a}$ & $\begin{array}{c}\text { D (x10 } \\
\left.{ }_{4}\right)\end{array}$ & V & $\mathbf{Y}_{\mathbf{X}}$ & $\begin{array}{c}\text { M(üs } \\
\text { t) }\end{array}$ & $\begin{array}{c}M(a l \\
\text { t) }\end{array}$ \\
\hline \multirow[t]{3}{*}{2} & S204 & 2,63 & $\begin{array}{c}2,9 \\
2\end{array}$ & $\begin{array}{c}0,5 \\
9\end{array}$ & 1,56 & 6,77 & $\begin{array}{c}0,4 \\
5\end{array}$ & 11,16 & 9,13 \\
\hline & S205 & 4,98 & $\begin{array}{c}3,1 \\
1\end{array}$ & $\begin{array}{c}0,6 \\
1 \\
\end{array}$ & 3,03 & $\begin{array}{c}13,1 \\
7\end{array}$ & $\begin{array}{c}0,4 \\
5 \\
\end{array}$ & 21,73 & 17,78 \\
\hline & S206 & 2,63 & $\begin{array}{c}2,9 \\
9\end{array}$ & $\begin{array}{c}0,6 \\
0\end{array}$ & 1,57 & 6,83 & $\begin{array}{c}0,4 \\
5\end{array}$ & 11,27 & 9,22 \\
\hline $\begin{array}{c}\text { Topla } \\
\text { m }\end{array}$ & & & & & 6,16 & $\begin{array}{c}26,7 \\
7\end{array}$ & & 44,16 & 36,13 \\
\hline \multirow[t]{3}{*}{1} & S104 & 2,63 & $\begin{array}{c}2,9 \\
2 \\
\end{array}$ & $\begin{array}{c}0,6 \\
9 \\
\end{array}$ & 1,82 & $\begin{array}{c}11,1 \\
4 \\
\end{array}$ & $\begin{array}{c}0,5 \\
8 \\
\end{array}$ & 14,20 & 19,22 \\
\hline & S105 & 4,98 & $\begin{array}{c}3,1 \\
1 \\
\end{array}$ & $\begin{array}{c}0,7 \\
1 \\
\end{array}$ & 3,52 & $\begin{array}{c}21,4 \\
8 \\
\end{array}$ & $\begin{array}{c}0,5 \\
8 \\
\end{array}$ & 27,39 & 37,06 \\
\hline & S106 & 2,63 & $\begin{array}{c}2,9 \\
9 \\
\end{array}$ & $\begin{array}{c}0,7 \\
0\end{array}$ & 1,84 & $\begin{array}{c}11,2 \\
1\end{array}$ & $\begin{array}{c}0,5 \\
8 \\
\end{array}$ & 14,29 & 19,34 \\
\hline $\begin{array}{c}\text { Topla } \\
\text { m }\end{array}$ & & & & & 7,18 & $\begin{array}{c}43,8 \\
3\end{array}$ & & 55,89 & 75,61 \\
\hline
\end{tabular}

Çizelge 8. Muto Metoduyla Çubuk ZB Uç Kuvvetleri

\begin{tabular}{|c|c|c|c|c|c|c|c|c|c|}
\hline $\begin{array}{l}\text { Kat } \\
\text { No }\end{array}$ & $\begin{array}{c}\text { Kolon } \\
\text { Adı }\end{array}$ & $\begin{array}{c}\mathbf{k}_{\mathrm{c}} \\
\left(\mathbf{x 1 0 ^ { 4 }}\right)\end{array}$ & $\mathbf{k}^{\prime}$ & $\mathbf{a}$ & $\begin{array}{c}\text { D (x10 } \\
4\end{array}$ & $\mathbf{V}$ & $\mathbf{Y}_{\mathbf{x}}$ & $\begin{array}{c}\text { M(üs } \\
\text { t) }\end{array}$ & $\begin{array}{c}\mathrm{M}(\mathbf{a l} \\
\mathbf{t})\end{array}$ \\
\hline \multirow[t]{3}{*}{2} & S204 & 2,63 & $\begin{array}{c}2,9 \\
2\end{array}$ & $\begin{array}{c}0,5 \\
9\end{array}$ & 1,56 & 8,35 & $\begin{array}{c}0,4 \\
5\end{array}$ & 13,78 & 11,27 \\
\hline & S205 & 4,98 & $\begin{array}{c}3,1 \\
1\end{array}$ & $\begin{array}{c}0,6 \\
1\end{array}$ & 3,03 & $\begin{array}{c}16,2 \\
5\end{array}$ & $\begin{array}{c}0,4 \\
5\end{array}$ & 26,82 & 21,94 \\
\hline & S206 & 2,63 & $\begin{array}{c}2,9 \\
9\end{array}$ & $\begin{array}{c}0,6 \\
0\end{array}$ & 1,57 & 8,43 & $\begin{array}{c}0,4 \\
5\end{array}$ & 13,92 & 11,39 \\
\hline $\begin{array}{c}\text { Topla } \\
\text { m }\end{array}$ & & & & & 6,16 & $\begin{array}{c}33,0 \\
4\end{array}$ & & 54,51 & 44,60 \\
\hline \multirow[t]{3}{*}{1} & $\begin{array}{l}\text { S104 } \\
\end{array}$ & 2,63 & $\begin{array}{c}2,9 \\
2\end{array}$ & $\begin{array}{c}0,6 \\
9\end{array}$ & 1,82 & $\begin{array}{c}13,7 \\
5\end{array}$ & $\begin{array}{c}0,5 \\
8\end{array}$ & 17,53 & 23,72 \\
\hline & S105 & 4,98 & $\begin{array}{c}3,1 \\
1\end{array}$ & $\begin{array}{c}0,7 \\
1\end{array}$ & 3,52 & $\begin{array}{c}26,5 \\
2\end{array}$ & $\begin{array}{c}0,5 \\
8\end{array}$ & 33,81 & 45,74 \\
\hline & S106 & 2,63 & $\begin{array}{c}2,9 \\
9 \\
\end{array}$ & $\begin{array}{c}0,7 \\
0 \\
\end{array}$ & 1,84 & $\begin{array}{c}13,8 \\
4\end{array}$ & $\begin{array}{c}0,5 \\
8 \\
\end{array}$ & 17,64 & 23,87 \\
\hline $\begin{array}{c}\text { Topla } \\
\text { m }\end{array}$ & & & & & 7,18 & $\begin{array}{c}54,1 \\
0\end{array}$ & & 68,98 & 93,33 \\
\hline
\end{tabular}

Çizelge 9. Muto Metoduyla Çubuk ZC Uç Kuvvetleri

\begin{tabular}{|c|c|c|c|c|c|c|c|c|c|}
\hline $\begin{array}{l}\text { Kat } \\
\text { No }\end{array}$ & $\begin{array}{c}\text { Kolon } \\
\text { Adı }\end{array}$ & $\begin{array}{c}\mathbf{k}_{\mathrm{c}} \\
\left(\mathbf{x 1 0}^{4}\right)\end{array}$ & $\mathbf{k}^{\prime}$ & $\mathbf{a}$ & $\begin{array}{c}\mathbf{D}(\mathbf{x 1 0} \\
4)\end{array}$ & $\mathbf{V}$ & $\overline{\mathbf{Y}_{\mathbf{x}}}$ & $\begin{array}{c}\text { M(üs } \\
\text { t) }\end{array}$ & $\begin{array}{c}\text { M(al } \\
\text { t) }\end{array}$ \\
\hline \multirow[t]{3}{*}{2} & S204 & 2,63 & $\begin{array}{c}2,9 \\
2\end{array}$ & $\begin{array}{c}0,5 \\
9\end{array}$ & 1,56 & $\begin{array}{c}10,8 \\
9\end{array}$ & $\begin{array}{c}0,4 \\
5\end{array}$ & 17,97 & 14,70 \\
\hline & S205 & 4,98 & $\begin{array}{c}3,1 \\
1 \\
\end{array}$ & $\begin{array}{c}0,6 \\
1 \\
\end{array}$ & 3,03 & $\begin{array}{c}21,2 \\
0 \\
\end{array}$ & $\begin{array}{c}0,4 \\
5 \\
\end{array}$ & 34,98 & 28,62 \\
\hline & S206 & 2,63 & $\begin{array}{c}2,9 \\
9 \\
\end{array}$ & $\begin{array}{c}0,6 \\
0\end{array}$ & 1,57 & $\begin{array}{c}11,0 \\
0\end{array}$ & $\begin{array}{c}0,4 \\
5\end{array}$ & 18,15 & 14,85 \\
\hline $\begin{array}{c}\text { Topla } \\
\text { m }\end{array}$ & & & & & 6,16 & $\begin{array}{c}43,0 \\
9\end{array}$ & & 71,09 & 58,17 \\
\hline \multirow[t]{3}{*}{1} & S104 & 2,63 & $\begin{array}{c}2,9 \\
2\end{array}$ & $\begin{array}{c}0,6 \\
9\end{array}$ & 1,82 & $\begin{array}{c}17,9 \\
3\end{array}$ & $\begin{array}{c}0,5 \\
8\end{array}$ & 22,86 & 30,93 \\
\hline & S105 & 4,98 & $\begin{array}{c}3,1 \\
1\end{array}$ & $\begin{array}{c}0,7 \\
1\end{array}$ & 3,52 & $\begin{array}{c}34,5 \\
8\end{array}$ & $\begin{array}{c}0,5 \\
8\end{array}$ & 44,09 & 59,65 \\
\hline & S106 & 2,63 & $\begin{array}{c}2,9 \\
9\end{array}$ & $\begin{array}{c}0,7 \\
0\end{array}$ & 1,84 & $\begin{array}{c}18,0 \\
5\end{array}$ & $\begin{array}{c}0,5 \\
8 \\
\end{array}$ & 23,01 & 31,13 \\
\hline $\begin{array}{c}\text { Topla } \\
\text { m }\end{array}$ & & & & & 7,18 & $\begin{array}{c}70,5 \\
6\end{array}$ & & 89,96 & $\begin{array}{c}121,7 \\
1\end{array}$ \\
\hline
\end{tabular}

Çizelge 10. Muto Metoduyla Çubuk ZD Uç Kuvvetleri

Çizelge 11. Muto Metoduyla Çubuk ZE Uç Kuvvetleri 
Çizelge 12 'de her bir zemin sınıfından elde edilen kolon uç momentleri bir arada gösterilerek değerler Şekil 7'de grafiğe aktarılmıştır.

\begin{tabular}{|c|c|c|c|c|c|c|c|c|c|c|c|}
\hline & & \multicolumn{2}{|c|}{$\mathbf{Z A}$} & \multicolumn{2}{|c|}{ ZB } & \multicolumn{2}{|c|}{$\mathbf{Z C}$} & \multicolumn{2}{|c|}{ ZD } & \multicolumn{2}{|c|}{$\mathbf{Z E}$} \\
\hline $\begin{array}{l}\text { Kat } \\
\text { No }\end{array}$ & $\begin{array}{l}\text { Kolo } \\
\text { n Adı }\end{array}$ & $\begin{array}{l}\mathbf{M}( \\
\text { üst) }\end{array}$ & $\begin{array}{l}\mathbf{M}( \\
\text { alt })\end{array}$ & $\begin{array}{c}\mathbf{M (} \\
\text { üst) }\end{array}$ & $\begin{array}{l}\mathbf{M}( \\
\text { alt })\end{array}$ & $\begin{array}{l}\mathbf{M}( \\
\text { üst) }\end{array}$ & $\begin{array}{l}\text { M( } \\
\text { alt })\end{array}$ & $\begin{array}{r}\text { M( } \\
\text { üst) }\end{array}$ & $\begin{array}{l}\text { M( } \\
\text { alt) }\end{array}$ & $\begin{array}{l}\text { M( } \\
\text { üst) }\end{array}$ & $\begin{array}{c}\text { M( } \\
\text { alt })\end{array}$ \\
\hline \multirow[t]{3}{*}{2} & S204 & $\begin{array}{c}6,4 \\
7\end{array}$ & $\begin{array}{c}5,3 \\
0\end{array}$ & $\begin{array}{c}6,8 \\
3\end{array}$ & $\begin{array}{c}5,5 \\
9\end{array}$ & $\begin{array}{l}11, \\
16\end{array}$ & $\begin{array}{c}9,1 \\
3\end{array}$ & $\begin{array}{l}13, \\
78\end{array}$ & $\begin{array}{l}11, \\
27\end{array}$ & $\begin{array}{l}17, \\
97\end{array}$ & $\begin{array}{l}14, \\
70\end{array}$ \\
\hline & S205 & $\begin{array}{l}12, \\
60\end{array}$ & $\begin{array}{l}10, \\
31\end{array}$ & $\begin{array}{l}13, \\
29\end{array}$ & $\begin{array}{l}10, \\
87\end{array}$ & $\begin{array}{l}21, \\
73\end{array}$ & $\begin{array}{l}17, \\
78\end{array}$ & $\begin{array}{l}26, \\
82\end{array}$ & $\begin{array}{l}21, \\
94\end{array}$ & $\begin{array}{c}34 \\
98\end{array}$ & $\begin{array}{l}28, \\
62\end{array}$ \\
\hline & S206 & $\begin{array}{c}6,5 \\
4\end{array}$ & $\begin{array}{c}5,3 \\
5\end{array}$ & $\begin{array}{c}6,9 \\
0\end{array}$ & $\begin{array}{c}5,6 \\
4\end{array}$ & $\begin{array}{l}11, \\
27\end{array}$ & $\begin{array}{c}9,2 \\
2\end{array}$ & $\begin{array}{l}13 \\
92\end{array}$ & $\begin{array}{l}11, \\
39\end{array}$ & $\begin{array}{l}18 \\
15\end{array}$ & $\begin{array}{l}14, \\
85\end{array}$ \\
\hline \multirow[t]{3}{*}{1} & S104 & $\begin{array}{c}8,2 \\
4\end{array}$ & $\begin{array}{l}11, \\
14\end{array}$ & $\begin{array}{c}8,6 \\
9\end{array}$ & $\begin{array}{l}11, \\
75\end{array}$ & $\begin{array}{l}14, \\
20\end{array}$ & $\begin{array}{l}19, \\
22\end{array}$ & $\begin{array}{l}17, \\
53\end{array}$ & $\begin{array}{l}23, \\
72\end{array}$ & $\begin{array}{l}22, \\
86\end{array}$ & $\begin{array}{l}30, \\
93\end{array}$ \\
\hline & S105 & $\begin{array}{l}15, \\
89 \\
\end{array}$ & $\begin{array}{l}21, \\
49\end{array}$ & $\begin{array}{l}16, \\
75\end{array}$ & $\begin{array}{l}22, \\
67\end{array}$ & $\begin{array}{l}27, \\
39\end{array}$ & $\begin{array}{l}37, \\
06\end{array}$ & $\begin{array}{c}33, \\
81\end{array}$ & $\begin{array}{l}45, \\
74 \\
\end{array}$ & $\begin{array}{l}44, \\
09\end{array}$ & $\begin{array}{l}59, \\
65\end{array}$ \\
\hline & S106 & $\begin{array}{c}8,2 \\
9\end{array}$ & $\begin{array}{l}11, \\
22\end{array}$ & $\begin{array}{c}8,7 \\
4\end{array}$ & $\begin{array}{l}11, \\
83\end{array}$ & $\begin{array}{l}14, \\
29\end{array}$ & $\begin{array}{l}19, \\
34\end{array}$ & $\begin{array}{l}17, \\
64\end{array}$ & $\begin{array}{l}23, \\
87\end{array}$ & $\begin{array}{c}23, \\
01\end{array}$ & $\begin{array}{c}31, \\
13\end{array}$ \\
\hline
\end{tabular}

Çizelge 12. Zemin Sınıflarına Göre Kolon Uç Momentleri

Çizelge 13 zemin sınıflarına göre hesaplanan kiriş uç momentlerini göstermektedir.

\begin{tabular}{|c|c|c|c|c|c|c|c|c|c|c|c|}
\hline \multirow[b]{2}{*}{$\begin{array}{l}K \\
\text { at }\end{array}$} & & \multirow[b]{2}{*}{$\begin{array}{c}\text { Ke } \\
\text { na } \\
\text { r }\end{array}$} & \multirow{2}{*}{$\begin{array}{c}\text { ZA } \\
\text { Mo } \\
\text { men } \\
t\end{array}$} & \multicolumn{2}{|c|}{ ZB } & \multicolumn{2}{|c|}{$\mathbf{Z C}$} & \multicolumn{2}{|c|}{ ZD } & \multicolumn{2}{|c|}{$\mathbf{Z E}$} \\
\hline & & & & $\begin{array}{c}\text { Mo } \\
\text { men } \\
t\end{array}$ & $\begin{array}{l}\text { Değ } \\
\text { işim }\end{array}$ & $\begin{array}{c}\text { Mo } \\
\text { men } \\
t\end{array}$ & $\begin{array}{l}\text { Değ } \\
\text { işim }\end{array}$ & $\begin{array}{c}\text { Mo } \\
\text { men } \\
t\end{array}$ & $\begin{array}{l}\text { Değ } \\
\text { işim }\end{array}$ & $\begin{array}{c}\text { Mo } \\
\text { men } \\
t\end{array}$ & $\begin{array}{l}\text { Değ } \\
\text { işim }\end{array}$ \\
\hline \multirow[t]{4}{*}{2} & \multirow{2}{*}{$\begin{array}{c}\mathbf{K} \\
\mathbf{1 0} \\
\mathbf{3}\end{array}$} & sol & 6,47 & 6,83 & $\begin{array}{l}5,5 \\
\% \\
\end{array}$ & $\begin{array}{c}11,1 \\
6\end{array}$ & $\begin{array}{c}72,4 \\
\%\end{array}$ & $\begin{array}{c}13,7 \\
8 \\
\end{array}$ & $\begin{array}{r}112, \\
8 \% \\
\end{array}$ & $\begin{array}{c}17,9 \\
7 \\
\end{array}$ & $\begin{array}{r}177, \\
6 \%\end{array}$ \\
\hline & & săg & 6,22 & 6,56 & $\begin{array}{l}5,5 \\
\%\end{array}$ & $\begin{array}{c}10,7 \\
3 \\
\end{array}$ & $\begin{array}{c}72,4 \\
\%\end{array}$ & $\begin{array}{c}13,2 \\
5\end{array}$ & $\begin{array}{l}112, \\
8 \% \\
\end{array}$ & $\begin{array}{c}17,2 \\
7\end{array}$ & $\begin{array}{l}177, \\
6 \%\end{array}$ \\
\hline & \multirow{2}{*}{$\begin{array}{c}K \\
10 \\
4\end{array}$} & sol & 6,38 & 6,73 & $\begin{array}{c}5,5 \\
\%\end{array}$ & $\begin{array}{c}11,0 \\
0\end{array}$ & $\begin{array}{c}72,4 \\
\%\end{array}$ & $\begin{array}{c}13,5 \\
7\end{array}$ & $\begin{array}{l}112, \\
8 \%\end{array}$ & $\begin{array}{c}17,7 \\
0\end{array}$ & $\begin{array}{l}177, \\
6 \%\end{array}$ \\
\hline & & săg & 6,54 & 6,90 & $\begin{array}{l}5,5 \\
\%\end{array}$ & $\begin{array}{c}11,2 \\
7\end{array}$ & $\begin{array}{c}72,4 \\
\%\end{array}$ & $\begin{array}{c}13,9 \\
2\end{array}$ & $\begin{array}{l}112, \\
8 \%\end{array}$ & $\begin{array}{c}18,1 \\
5\end{array}$ & $\begin{array}{l}177, \\
6 \%\end{array}$ \\
\hline \multirow[t]{4}{*}{1} & \multirow{2}{*}{$\begin{array}{c}\mathrm{K} \\
\mathbf{1 0} \\
\mathbf{3}\end{array}$} & sol & $\begin{array}{c}13,5 \\
3\end{array}$ & $\begin{array}{c}14,2 \\
7\end{array}$ & $\begin{array}{l}5,5 \\
\%\end{array}$ & $\begin{array}{c}23,3 \\
4\end{array}$ & $\begin{array}{c}72,4 \\
\%\end{array}$ & $\begin{array}{c}28,8 \\
0\end{array}$ & $\begin{array}{l}112, \\
8 \%\end{array}$ & $\begin{array}{c}37,5 \\
6\end{array}$ & $\begin{array}{l}177, \\
6 \%\end{array}$ \\
\hline & & sağ & $\begin{array}{c}12,9 \\
4\end{array}$ & $\begin{array}{c}13,6 \\
4\end{array}$ & $\begin{array}{l}5,5 \\
\%\end{array}$ & $\begin{array}{c}22,3 \\
1\end{array}$ & $\begin{array}{c}72,4 \\
\%\end{array}$ & $\begin{array}{c}27,5 \\
4\end{array}$ & $\begin{array}{l}112, \\
8 \%\end{array}$ & $\begin{array}{c}35,9 \\
1\end{array}$ & $\begin{array}{l}177, \\
6 \%\end{array}$ \\
\hline & \multirow{2}{*}{$\begin{array}{c}K \\
10 \\
4\end{array}$} & sol & $\begin{array}{c}13,2 \\
6\end{array}$ & $\begin{array}{c}13,9 \\
8\end{array}$ & $\begin{array}{l}5,5 \\
\%\end{array}$ & $\begin{array}{c}22,8 \\
6\end{array}$ & $\begin{array}{c}72,4 \\
\%\end{array}$ & $\begin{array}{c}28,2 \\
2\end{array}$ & $\begin{array}{l}112, \\
8 \%\end{array}$ & $\begin{array}{c}36,8 \\
0\end{array}$ & $\begin{array}{l}177, \\
6 \%\end{array}$ \\
\hline & & săg & $\begin{array}{c}13,6 \\
4\end{array}$ & $\begin{array}{c}14,3 \\
8\end{array}$ & $\begin{array}{c}5,5 \\
\%\end{array}$ & $\begin{array}{c}23,5 \\
2\end{array}$ & $\begin{array}{c}72,4 \\
\%\end{array}$ & $\begin{array}{c}29,0 \\
3\end{array}$ & $\begin{array}{l}112, \\
8 \%\end{array}$ & $\begin{array}{c}37,8 \\
6\end{array}$ & $\begin{array}{l}177, \\
6 \%\end{array}$ \\
\hline
\end{tabular}

Çizelge 13. Zemin Sınıflarına Göre Kiriş Uç Momentleri

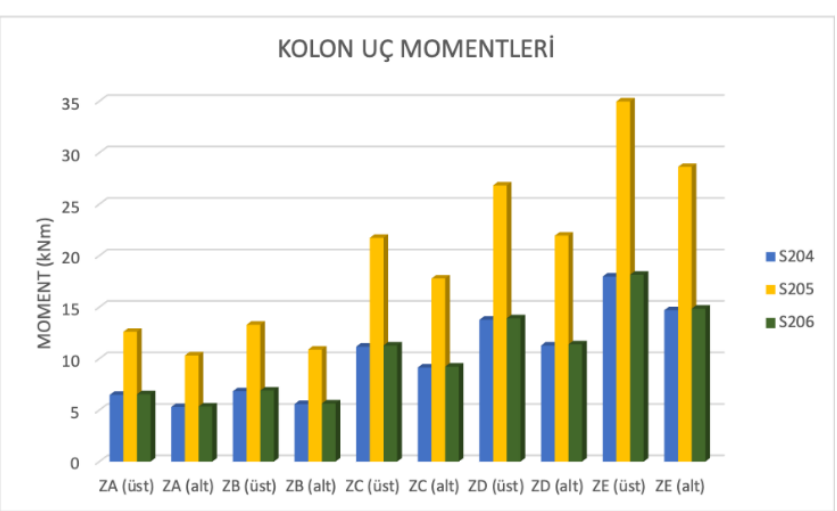

Şekil 7. Zemin Sınıflarına Göre İkinci Kat Kolon Uç Momentleri

\section{Sonuçlar}

TBDY-2018 üzerine yap1 gelecek olan zeminleri, eski yönetmeliğe göre çok daha geniş bir düzlemde ele alarak zeminlerde detaylı bir sinıflandırmaya gitmiştir. $\mathrm{Bu}$ kapsamda farklı zemin sınıflarını ile yer hareketi düzeylerinin betonarme çerçeve bir yapı üzerinde etkisi çalışılmıştır. Yapılan analizler sonucunda yerel zemin katsayılarına bağlı olarak 8 farklı spektrum grafiği ve zemin sınıflarına bağlı olarak kolon ve kiriş uç moment etkisi değerlendirilmiştir.

Yerel zemin etki katsayılarına bağlı olarak değişen $\mathrm{S}_{\mathrm{DS}}$ değerleri genel olarak ZA ile ZC arası artış gösterirken ZD ve ZE zemin sınıflarında bir azalma göstermiştir. İyi olarak kabul edilen zemin sınıfında en kötü zemin sınıfına doğru $\mathrm{S}_{\mathrm{DS}}$ değerlerinde artış meydana gelmiştir.

İvme spektrumları kullanılacağı konuma göre değişiklik göstermesinin yanı sıra iyi zemin (ZA) standart spektrum değerlerine yakın çıkarken kötü zemin (ZE) ise daha büyük ivme değerleri göstermiştir.

Kolon ve kirişlere gelen yükler ZA zemin sınıfı temel alındığında \%178'lere kadar arttığı gözlemlenmiştir. ZA ve ZB zemin sınıflarına ait veriler arasında sadece $\% 5,5$ 'lik bir farkın oluştuğu, ancak zemin sınıfı ZC olduğunda ise gelen yük oranı \% 74,4 olarak bulunmuştur.

Sonuç olarak, yapıların inşa edildiği zeminlerin sınıfı ile herhangi bir deprem anında yapıya gelecek deprem kuvvetleri ve bu kuvvetlerin etkisiyle de yapının kesit tesirleri büyük oranda değiştirmektedir. Yapı tasarımlarında deprem kuvvetlerin etkisi yadsınamayacak derecede yapıya etkimektedir.

\section{Çıkar çatışması}

Yazarlar arasında çıkar çatışması bulunmamaktadır.

\section{Kaynaklar}

[1] DBYBHY. (2007). Deprem Bölgelerinde Yapılacak Binalar Hakkında Yönetmelik. Ankara: Bayındırlık ve İskan Bakanlığı.

[2] TBDY. (2018). Türkiye Bina Deprem Yönetmeliği. Ankara: Afet ve Acil Durum Yönetimi Başkanlığı.

[3] Işık, E. (2016). Consistency of the rapid assessment method for reinforced concrete buildings. Earthquakes and Structures, $11(5), \quad 873-885$. https://doi.org/10.12989/eas.2016.11.5.873

[4] Özcebe, G., Yucemen, M. S., Aydogan, V., \& Yakut, A. (2003). Preliminary seismic vulnerability assessment of existing reinforced concrete buildings in Turkey. In Seismic Assessment and Rehabilitation of Existing Buildings (pp. 29-42). Springer, Dordrecht.

[5] Arslan, M. H. (2010). An evaluation of effective design parameters on earthquake performance of RC buildings using neural networks. Engineering Structures, 32(7), 1888-1898.

[6] Işık, E., Karasin, İ.B., Ulu, A.E. (2020). Eğimli Zeminlerde İnşa Edilen Betonarme Binaların Deprem Davranışlarının İncelenmesi . Avrupa Bilim ve Teknoloji Dergisi , (20) , 162-170. DOI: 10.31590/ejosat.757763.

[7] Yakut, A. (2004). Preliminary seismic performance assessment procedure for existing RC buildings. Engineering Structures, 26(10), 1447-1461. https://doi.org/10.1016/j.engstruct.2004.05.011

[8] Karaşin, İ. B., Işı1k, E., Karaşin, A., \& Özdemir, M. (2017). Betonarme Yapılarda Tepe-Yamaç Etkisinin Yap1 Performansina Etkisi. International Conference on Multidisciplinary, Science, Engineering and Technology (IMESET'17), Bitlis, Türkiye. 
[9] Tezcan, S. S., Bal, I. E., \& Gulay, F. G. (2011). P25 scoring method for the collapse vulnerability assessment of $\mathrm{R} / \mathrm{C}$ buildings. Journal of the Chinese Institute of Engineers, 34(6), 769 781.https://doi.org/10.1080/02533839.2011.591548

[10] Sreerama, A. K., \& Ramancharla, P. K. (2013, October). Earthquake behavior of reinforced concrete framed buildings on hill slopes. In International Symposium on New Technologies for Urban Safety of Mega Cities in Asia (USMCA 2013).

[11] Šipoš, T. K., \& Hadzima-Nyarko, M. (2017). Rapid seismic risk assessment. International Journal of Disaster Risk Reduction, $\quad 24, \quad 348-360$. https://doi.org/10.1016/j.ijdrr.2017.06.025

[12] Işık, E., Özdemir, M., \& Karaşin, İ. B. (2018). Performance analysis of steel structures with A3 irregularities. International Journal of Steel Structures, 18(3), 1083-1094. https://doi.org/10.1007/s13296-018-0046-6

[13] Hadzima-Nyarko, M., \& Kalman Sipos, T. (2017). Insights from existing earthquake loss assessment research in Croatia. Earthquakes and Structures, 13(4), 365-375. https://doi.org/10.12989/eas.2017.13.4.401

[14] Xian, L., He, Z., \& Ou, X. (2016). Incorporation of collapse safety margin into direct earthquake loss estimate. Earthquakes and Structures, 10(2), 429-450. https://doi.org/10.12989/eas.2016.10.2.4

[15] Arslan, M. H., Köroğlu, M. A., \& Köken, A. (2008). Binaların yapısal performansının statik itme analizi ile belirlenmesi. Yapı Teknolojileri Elektronik Dergisi, 4(2), 7184.
[16] Başaran, V., (2018). Türkiye Bina Deprem Yönetmeliğine (TBDY 2019) Göre Afyonkarahisar İçin Deprem Yüklerinin Değerlendirilmesi, Afyon Kocatepe University Journal of Science and Engineering. 18, 10281035.

[17] Başaran, V., Hiçyılmaz, M., (2020). Betonarme Çerçevelerde Farklı Deprem Yer Hareketi Düzeyi Etkilerinin Incelenmesi, Journal of Innovations in Civil Engineering and Technology. 2(1), 27-41.

[18] Türkiye Deprem Haritaları İnteraktif Web Uygulamas1, Erişim adresi: https://tdth.afad.gov.tr/ (Erişim tarihi: 25.01.2021)

[19] Chopra, A. K., \& Goel, R. K. (2002). A modal pushover analysis procedure for estimating seismic demands for buildings. Earthquake Engineering \& Structural Dynamics, 31(3), 561-582. https://doi.org/10.1002/eqe.144

[20] Ademovic, N., Hrasnica, M., \& Oliveira, D.V. (2013). Pushover analysis and failure pattern of a typical masonry residential building in Bosnia and Herzegovina. $\begin{array}{llll}\text { Engineering } \quad \text { Structures, } & 50, & 13-\end{array}$ https://doi.org/10.1016/j.engstruct.2012.11.031

[21] Işık, E., \& Kutanis M. (2015). Performance based assessment for existing residential buildings in Lake Van basin and seismicity of the region. Earthquakes and Structures, 9(4), 893-910. https://doi.org/10.12989/eas.2015.9.4.893 